\title{
Brand Endorsements: An Exploratory Study into the Effectiveness of Using Video Game Characters as Brand Endorsers
}

\author{
Jake Shelton \\ Department of Marketing, University of the Witwatersrand, \\ Private Bag 3, Wits, 2050, Johannesburg, South Africa \\ Email: jake.shelton@students.wits.ac.za \\ Norman Chiliya \\ Department of Marketing, University of the Witwatersrand, \\ Private Bag 3, Wits, 2050, Johannesburg, South Africa \\ Email: Norman.Chiliya@wits.ac.za
}

\author{
Doi:10.5901/mjss.2014.v5n14p260
}

\begin{abstract}
Celebrity endorsements have been established as one of the most preferred methods of advertising by marketers (Patel, 2009). Biswas, Hussain and O'Donnell (2009) enumerates five specific benefits of employing celebrity endorsers for a brand, they can be summarised as follows: drawing attention, crisis management, brand repositioning, global marketing, and boosting sales. However the benefits of using a celebrity endorser can be markedly reversed if the celebrity, is involved in a controversial incident, loses credibility by endorsing too many brands, suddenly changes their image, overshadows the brand which is being endorsed, experiences a drop in popularity, is the centre of negative publicity, or fails to perform within their specific career (Erdogan, 1999). As a solution to these problems this research has investigated the use of video game characters as celebrity brand endorsers. Video game characters are celebrities in their own right but they are not plagued by the same risks and problems as ordinary celebrities (Avery, Ferrand, Nicholas \& Rowley, 2006; Shimp \& Till, 1998). This exploratory study used a quantitative research approach. A self-administered questionnaire using a 7-point Likert scale was developed and piloted. The questionnaire was distributed at the University of the Witwatersrand to a sample group of 484 respondents between the ages of 18 to 25. Fictitious adverts were used as stimuli during the questionnaire. Convenience sampling was used because of time and monetary constraints. The linear regression results proved that video game characters are effective as brand endorsers and can be used in place of an ordinary celebrity to increase the purchase intentions of the target audience. It can be recommended that video game companies seek opportunities to create partnerships with marketers to use their characters as brand endorsers.
\end{abstract}

Keywords: Brand Endorsement, Video Game Characters, Celebrities, Advertising

\section{Introduction}

Celebrity endorsements have been established as one of the most preferred methods of advertising by marketers (Patel, 2009). According to Ohanian (1991), Patel (2009) and Pornpitakpan (2003a), this popularity of celebrity endorsement is due to advertisers' belief that a message which is delivered by a well-known personality will attract more attention, as well as improve recall for consumers. Patel (2009) included that celebrities add a new dimension to the product, thereby using their fame to generate this recall.

There are other reasons for using a celebrity endorser. One such reason is that the celebrity acts as a quick means for differentiating the brand from its competitors in the minds of consumers. The right celebrity can deliver the brand message without the need for elaborated story telling. Also the celebrity endorser acts almost as a guarantee for the product lending the brand credibility (Patel, 2009). Jaiprakash (2008) adds that when used effectively a celebrity endorsement can play a valuable role in developing brand equity and also may enhance a brand's competitive position.

The development of brand equity is important as every year marketers spend enormous amounts of money on celebrity endorsement contracts based on the belief that these celebrities will be effective spokespeople for their brands (Jaiprakash, 2008). (Amos, Holmes, \& Strutton (2008) state that there is a substantial amount of research on this topic, much of this research suggests that including a celebrity in advertising campaigns will materially improve financial returns for the companies that employ them. Also Atkin and Block (1983) reveal that advertisements which feature celebrity 
figures produce consistently more favourable results than those that do not.

According to Avery, Farrand, Nichols, and Rowley (2006) a new industry has emerged on a global scale which trumps the video and music industry in terms of size and growth, which is the gaming industry. Even more important than the size of this new industry is its potential as a new market, which has been up till recently ignored by marketers (Avery et al, 2006). Recently developments in the gaming industry have created completely new cultural icons as well as social structures (Avery et al, 2006). According to Avery et al (2006) in the future game characters and game developers will be seen as the new celebrities and directors within the entertainment industry globally.

Avery et al (2006); Peter (2011) and Untal (2012) believe that the massive growth of the gaming console has led to a huge audience of gamers globally. They further state that these new gamers represent a substantial new segment of consumers which businesses can target. There are a multitude of opportunities opening up for brands of all types to offer many different products to this new segment. At all levels we will see a growing importance of media which target gamers specifically, such as magazines or websites, many of which will be unfamiliar in content and style to conventional marketers and brand owners (Avery et al, 2006).

The gaming phenomenon is something which marketers, advertisers and brand owners cannot afford to ignore as gamers have been creating a lucrative new market on a global scale (Avery et al, 2006; Peter, 2011; Untal, 2012).

This research focused on the use of these video game characters, emerging from this phenomenon as the new celebrities of this gamer culture, as brand endorsers. Also this research has investigated the effectiveness of using a game character instead of a celebrity to promote a brand or product message. The objectives of this research were to identify the appropriateness of using game characters to promote brands and also to identify how well consumers perceive these characters, along the constructs of attractiveness, trustworthiness and expertise.

There is currently very little research done in the area of game characters endorsing brands. However, there is evidence of such advertising tactic having been employed in the past. A successful example occurred between 1999 and 2001 when the brand Lucozade teamed up with the creators of Tomb Raider (Avery et al, 2006; Peter, 2011).

\section{Problem Statement}

Celebrity endorsements have been proven to be an effective advertising tool; however a problem comes in when the celebrity falls into controversy or if they fail within their field or profession (Patel, 2009). Often an endorsed brand's success relies on the performance of the celebrity. The celebrity's performance refers to the level of achievement which a celebrity may obtain at a specific time within their profession (Amos, et al., 2008). The problem however is that there is no guarantee that the celebrity can continuously perform at a high enough level to remain popular over the length of their career (Amos, et al., 2008).

Marketers who use celebrities to endorse their brands do so in the hope that their target audiences will have positive feelings towards the celebrity and that those positive feelings will then be transferred to the brand through the endorsement and thus enhance the brands standing (Shimp \& Till, 1998). Although if the celebrity gets caught up in controversy then the endorsement by that celebrity can have a negative impact on the brand (Patel, 2009), and because of this, at times, celebrity endorsers may become liabilities to the brands being endorsed (Shimp \& Till, 1998).

According to Pornpitakpan (2003b) if a celebrity receives bad publicity, after endorsing the brand, then the image of the product as well as that of the sponsoring firm will both be affected. Amos, Holmes, and Strutton (2008) argue though that there needs to be a strong association between the brand and the celebrity present before negative information about the celebrity can have any major effect on the perceptions of the brand. Yet Amos et al (2008) do agree that negative information about a celebrity endorser may put the firms and brands image at risk, such as when Michael Jackson's child molestation charges created a surge of negative publicity, which impacted negatively on his effectiveness as an endorser for Pepsi (Amos, et al., 2008).

A further problem with the use of celebrities currently is that the status of celebrity decays with age (Anderson, Kurzman, Key, Lee, Moloney, Silver, \& Van Ryn, 2007). This describes the notion that celebrities can become out-of-date as they age, and most celebrities are unable to retain the same level of celebrity status as their careers mature (Anderson et al., 2007). Also there are few examples of celebrities who die young, and during their height of fame, to become remembered as cultural icons such as: James Dean, Che Guevara, and Marilyn Monroe. Furthermore Anderson, et al (2007) states that the rate of decay for celebrities has accelerated over the last century.

The problems with celebrity endorsement lie in the fact that marketers cannot control every aspect of the celebrity. Marketers have no control over the celebrities future behaviour, therefore the brand is always at risk of negative publicity caused by the celebrity (Shimp \& Till, 1998). Secondly, the marketers cannot control the performance of the celebrity within the celebrity's field or profession (Amos, et al., 2008). Lastly the level of celebrity status which an endorser enjoys 
may decay with time (Anderson, et al., 2007).

Video game characters are celebrities in their own right but they are not plagued by the same risks and problems as ordinary celebrities (Avery, et al., 2006). First of all video game characters do not suffer the same aging problem as traditional celebrities (Avery, et al., 2006) and video game characters do not have the same problem of celebrity decay as Anderson, et al (2007) mentioned for traditional celebrities.

Secondly a game character is created by game makers who have complete control over the characters actions. There is no chance of the character failing in their profession (Avery et al, 2006).

Finally Avery et al (2006), describes a game characters personality as being "bullet proof", this is because the game character cannot get messily divorced or get caught experimenting with drugs. Game characters cannot behave unpredictably and risk the reputation of the brand by behaving in a controversial way (Avery et al, 2006). Game characters are fictional, animated personalities and so they are generally immune to negative publicity (Shimp \& Till, 1998).

In summary the problems which are generally found in using traditional celebrity endorsements may be addressed by using popular game characters as a celebrity for endorsement purposes. In the case of the Lara Croft endorsement of Lucozade, Avery et al (2006) stated that the partnership was mutually beneficial for all the parties involved, and the association with Lara improved Lucozade's sales. This is evidence of the effectiveness of using such a campaign to influence purchase intentions towards an endorsed brand (Avery et al, 2006).

\section{Primary and Secondary Objectives}

\subsection{Primary Objective}

The primary research objective of this exploratory study is to investigate the effectiveness of using a video game character in place of a1 celebrity to endorse a brand.

\subsection{Secondary objectives}

The following secondary objective were identified in order to achieve the primary research aim

(a) To conduct a literature review to identify and define concepts associated with brand endorsement and to identify the properties of celebrities and game characters to see if they are interchangeable.

(b) To investigate whether there is a difference between the responses of those respondents which play video games and those respondents which do not play video games in relation to their purchase intentions.

\section{Literature Review}

This strategy of using video game characters as brand endorsers has been used in the past; the first example of this is the brand of energy drink named Lucozade being endorsed by the famous Tomb Raider heroine, Lara Croft (Avery, et al., 2006). The aim of this strategy for Lucozade was to make the brand more attractive to the core 18 to 24 year old market by building a campaign around a popular game character (Avery, et al., 2006). Although this campaign used a game character as an endorser, the campaign was not aimed specifically at those consumers who played the games but also to non-gamers in the target market (Avery, et al., 2006).

Thus, it can be seen that video game characters are not only able to promote products which are embedded within the video games themselves, but also could be used to promote products in real life (Bustami \& Fikry, 2012).

Although previously there are many examples of cartoon characters reaching celebrity status, there was no precedent before the introduction of Lara Croft for celebrities to emerge from the video game industry (Avery, et al., 2006). The new gaming phenomenon is something that no marketer, brand owner, or advertiser can afford to ignore (Avery, et al., 2006).

There has been experimentation with marketing and games via certain platforms such as Facebook, but Csernayanszky (2012) and Avery, et al (2006) state that these are not tools built for marketers and do not offer much in terms of depth of content or audience diversity (Csernyanszky, 2012). According to Csernyanszky (2012) marketers and game designers share common goals and should work together to strengthen their positions.

In the case of Lara Croft endorsing Lucozade, the partnership proved to be mutually beneficial for both of their parties concerned, the association with Lara Croft boosted the sales of Lucozade, at the same time it helped to drive consumers to the Tomb Raider games (Avery, et al., 2006; Peter, 2011). 
A more recent case where video game characters were used as brand endorsers is Prada using Square Enix's Final Fantasy XIII-2 characters Lightning, Noel, Snow, Sazh, and Hope as endorsers for their 2012 Spring/Summer men's collection (VideoGamer, 2012). There is a magnitude of possibilities when it comes to blending advertising and video game characters; it is possible that in the near future video game heroes will be used more often to endorse brands (Peter, 2011). This strategy is an opportunity for brands to reach a fast growing segment of gamers (Peter, 2011). Gamers represent a significant new group of consumers which businesses are able to target, and there are multiple new opportunities opening up for brands and products of all types (Avery, et al., 2006). Video games are one of the fastestgrowing industries, and also the newest form of mass media (Caperton, 2012; Lamothe, 2012).

There is an outdated belief that all video gamers are young boys however research shows that 82 percent of game players are over the age of 18, in fact boys under the age of 17 accounts for only 13 percent of gamers (Caperton, 2012). More grown-ups than young people play video games, more than half of all American adults play video games of some kind (Jones, Lenhart \& Macgill, 2008). However younger adults are also significantly more likely than any other gamer group to play games (Jones, et al., 2008). Female gamers make up $40 \%$ of the gamer segment (Jackson, 2011). In fact women over the age of 18 represent the fastest growing market for video games (Caperton, 2012).

The gaming industry continues to grow at an incredible rate (Lamothe, 2012), in the United States the industry brought in more than $\$ 10.5$ billion in revenue, that is 273 million units sold in the year 2009 (Jackson, 2011). In the South Africa, the gaming industry continues to grow; in 2011 the gaming industry made over R1.7 billion in revenue. In 2010 there were 3.48 million individual games sold and this number increased to 3.86 million games sold in 2011 (Whitford, 2012).

\section{The Hypothesized Model}

The model which was used in this paper is a modified version of the source credibility model. The modified source credibility model is illustrated in figure 1. The following variables gender and engagement with video game characters were added to the source credibility model. This modified model was used to investigate the effectiveness of using a video game character as a brand endorser.

Figure 1: The Modified Source Credibility Model

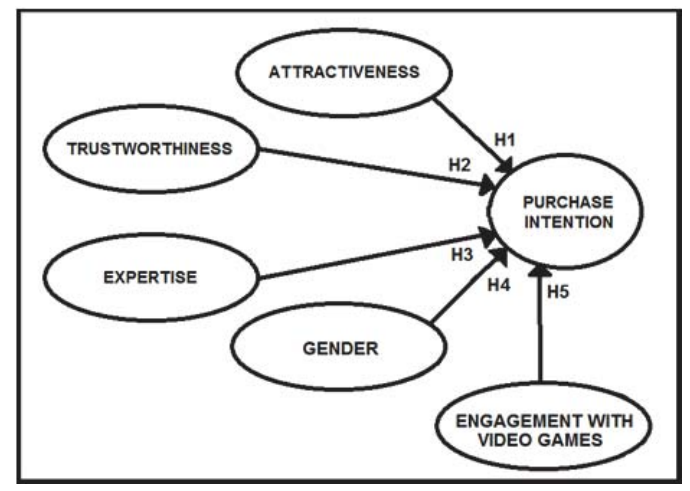

Source: Adapted from Ohanian (1990) and Pornpitakpan (2003a)

This model is modified from the original model developed by Ohanian (1990) and Pornpitakpan (2003a). This model includes a construct to test the effect which the gender of the respondent has on the purchase intentions of those respondents. Secondly this model also includes a construct of engagement with video games. This added construct is simply to test whether there is a difference in the purchase intentions of respondents who play video games versus those respondents who do not play video games.

The credibility of a source can be defined as the extent to which a message source is perceived as having expertise which is relevant to the communication topic and the extent to which the source can be trusted to provide an objective opinion on the subject (Jaiprakash, 2008). The term source credibility is commonly used to denote a message source's characteristics that positively affect the receiver's acceptance of a message (Ohanian, 1990). The more 
credibility that a source possesses, then the better the image created for the brand that is being endorsed (Sliburyte, 2009).

Patel (2009) also believes that if a message source is perceived as being credible, then the perceived quality of the product which is being endorsed will be higher. This is beneficial to marketers because a higher perceived quality of a brand is believed to drive consumers to choose that brand over competitive brands (Huang \& Radder, 2008). The credibility of the product endorser affects the persuasiveness of the advertisement when the advertisement contains a low involvement product (Cacioppo, et al., 1983). According to Cacioppo, et al. (1983) the celebrity status of the message source has no effect on attitudes when the advertisement concerns a product of high involvement.High credibility becomes even more important when consumers hold a negative view of the brand, because the credible source prevents counterarguments to the message and thus as a result the message becomes more persuasive (Breen, et al., 2003).

The model which is illustrated in figure 1 is modified from the model used by Pornpitakpan (2003a). This model was first developed by Ohanian (1990); its reliability was then tested by Ohanian (1991) and also by Pornpitakpan (2003a; 2003b). The model demonstrates that there are three components of brand endorsements that influence the purchase intentions of consumers; these are the perceived Attractiveness, Expertise, and Trustworthiness of the message source. According to Ohanian (1990) and Pornpitakpan (2003a) all three of these constructs correlate with one another and also all three have a distinctive effect on purchase intentions for consumers.

The more favourable a consumer's perceptions of these three credibility components are, the more the endorser is viewed as being a credible source of brand information and a credible representation for the brand (Lukas \& Seno, 2005). The constructs of Attractiveness, Trustworthiness, and Expertise are each made up of five indicators respectively (Ohanian, 1990). These are constructs and the related indicators identified in fig.1 are discussed in greater detail below.

The analysis of these elements looks at the score given to the brand endorser and correlates them to the purchase intention. The higher the score for each element of perceived attractiveness, expertise, and trustworthiness then the higher the purchase intention is likely to be, not taking into account the fit between the endorser and the product being endorsed (Pornpitakpan, 2003a). The score for each of these components are based on the indicators of each of these components respectively (Pornpitakpan, 2003a). These constructs and their respective indicators are described in more detail in the following sections.

\subsection{Attractiveness}

Attractiveness is an important dimension of source credibility (Ohanian, 1991). Most adverts make use of endorsers who are physically attractive as most consumers tend to form positive stereotypes about such people, and in addition physically attractive communicators are more successful in changing consumers' beliefs than unattractive communicators(Ohanian, 1991). Physical attractiveness is a significant aspect in an individual's initial judgement of another person, especially of a message source(Ohanian, 1990).

Attractive communicators are consistently more liked than unattractive communicators and have a more positive impact on the products with which they are associated (Ohanian, 1990). Erdogan (1999) found that an attractive endorser enhances attitudes towards both the advertisement and also the brand. Further than that Erdogan (1999) also found that an attractive endorser creates more purchase intentions than an unattractive endorser. One explanation for these findings is that an attractive message source tends to receive more attention than a less attractive source (Jaiprakash, 2008). Austad and Silvera (2004) however suggest that these positive attitudes from admiration of or perceived similarity to the message source.

Consumers like products more when they are endorsed by an attractive celebrity than when they are endorsed by an unattractive celebrity, and also attractive celebrities create more purchase intentions than unattractive celebrities (Erdogan, 1999; Sliburyte, 2009). Research has also shown that a physically attractive endorser can facilitate attitude change towards the brand being endorsed(Jaiprakash, 2008).

However some argue that the attractiveness construct for a brand endorser is multi-dimensional in nature (Amos, et al., 2008). Sliburyte (2009) suggests that an endorser's attractiveness is not limited to their physical characteristics but may also encompass such non-physical characteristics as intelligence, grace, or charisma. Amos, Holmes, and Strutton (2008) agree stating that the attractiveness construct encompasses not only physical attractiveness but also other virtuous characteristics which consumers might perceive as attractive about the endorser. It has also been argued that attractiveness encompasses familiarity, similarity and also likeability of the product endorser (Breen, et al., 2003). Consumers are more likely to be influenced by an endorser with whom they feel a sense of similarity (Alijosiene, et al., 2007). Erdogan (1999) states that, in certain circumstances, the qualities of a celebrity may be inappropriate, irrelevant, or sometimes even undesirable. 
Austad and Silvera (2004) disagree with the conventional belief of attractiveness. Austad and Silvera (2004) state that it is not the perceived levels of attractiveness, likability, or similarity of the endorser which influence the attitudes towards the endorsed product; but instead it is the endorser's sense of style and the endorser's perceived knowledge of the product which is most important in influencing attitudes.

The attractiveness aspect of a message source tends to have a greater impact on persuasion under conditions of low involvement rather than conditions of high involvement (Cacioppo, et al., 1983). Under conditions of low involvement, consumers' attitudes tend to be affected by simple acceptance and rejection cues within the message context, such as the perceived attractiveness of the message source, and are less affected by the quality of the argument(Cacioppo, et al., 1983).

For the purpose of this model the component of attractiveness were measured mostly on the physical characteristics of the brand endorser. The attractiveness component was measured using the scale developed by Ohanian (1990). The scale was made up of five indicators which the component was evaluated on, they are listed below:

- Attractive - Unattractive

- Classy - Not Classy

- Beautiful - Ugly

- Elegant - Plain

- Sexy - Not Sexy

This scale was used to investigate the perceived level of attractiveness for the video game characters which were used in this study. It measured the attractiveness of these characters and also the effect of attractiveness on the purchase intentions of the consumers involved in the study.

Austad and Silvera (2004) state that the importance of attractiveness is limited by the degree to how well the endorser's attractiveness fits with the advertised product. For example: physical attractiveness might be useful when selling beauty care products but not when selling computer software.

\subsection{Trustworthiness}

The trustworthiness component in a brand endorsement is based on the consumer's degree of confidence in, and their level of acceptance of, the message source and also the message (Ohanian, 1990; Pornpitakpan, 2003b). According to Ohanian (1991) trustworthiness refers to a consumer's confidence in the endorser for providing information in an honest and objective manner.

Trustworthiness is highly correlated with consumers' perceived similarity to the message source, it is also correlated to the source's perceived expertise, and the source's perceived attractiveness (Ohanian, 1990). Friedman and Friedman (1979) believe that trustworthiness is most likely the most significant dimension underlying the credibility of a source. The perceived trustworthiness of a message source has been shown to have a greater effect on attitude change than perceived expertise (Amos, et al., 2008). Trustworthiness is an important predictor of the effectiveness of a brand endorsement (Amos, et al., 2008; Austad \& Silvera, 2004).

The trustworthiness component was measured using the scale developed by Ohanian (1990). The scale was made up of five indicators which the component was evaluated on, they are listed below:

- Trustworthy - Untrustworthy

- Dependable - Undependable

- Honest - Dishonest

- Reliable - Unreliable

- Sincere - Insincere

This scale was used to investigate the perceived level of trustworthiness for the video game characters which were used in this study. It measured the trustworthiness of these characters and also the effect of trustworthiness on the purchase intentions of the consumers involved in the study.

An endorser's trustworthiness is an important factor for credibility and it is highly correlated with the attractiveness of the endorser (Lukas \& Seno, 2005). Celebrity endorsers are perceived to be both more competent and more trustworthy than non-celebrity endorsers, and as a result of this consumers tend to have more positive feelings towards adverts which feature celebrity endorsers in comparison to advertisements which feature non-celebrity endorsers (Atkin \& Block , 1983). 


\subsection{Expertise}

The perceived expertise of a brand endorser may be defined as the degree to which a message source is perceived to be a source of valid testimonials (Amos, et al., 2008; Ohanian, 1991). Expertise refers to the experience, knowledge, or skills which are possessed by a brand endorser (Erdogan, 1999; Austad \& Silvera, 2004). It does not actually make a difference if the source is really an expert in relation to the product as long as the target audience perceives the endorser as an expert on the subject.

Pornpitakpan (2003b) and Erdogan (1999) state that: an expert source will influence the perceptions of the product which is being endorsed. A brand endorser which is perceived as being more expert has been found to be more persuasive; and has been found to produce more purchase intentions than when compared to non-expert endorsers (Ohanian, 1991).

A receiver's perception of the endorser's expertise positively influences the effectiveness of the source (Amos, et al., 2008). When looking at persuasive communications the source's perceived level of expertise will generally have a positive effect on attitude change (Ohanian, 1990; McCracken, 1989).

The expertise aspect of a message source tends to have a greater impact on persuasion under conditions of low involvement rather than conditions of high involvement (Cacioppo, et al., 1983). Under conditions of low involvement, consumers' attitudes tend to be affected by simple acceptance and rejection cues within the message context, such as the perceived expertness of the endorser, and are less affected by the quality of the argument (Cacioppo, et al., 1983).

Suggested that the expertise of a brand endorser is the most important parameter to measure the effectiveness of brand endorsement.

The expertise component was measured using the scale developed by Ohanian (1990). The scale wass made up of five indicators which the component was evaluated on, they are listed below:

- Expert - Non-expert

- $\quad$ Experienced - Inexperienced

- Knowledgeable - Unknowledgeable

- Qualified - Unqualified

- $\quad$ Skilled - Unskilled

This scale was be used to investigate the perceived level of expertise for the video game characters which were used in this study. It measured the expertise of these characters and also the effect of expertise on the purchase intentions of the consumers involved in the study.

\subsection{Purchase Intention}

In order to measure purchase intention Pornpitakpan (2003a) used five indicators which can be used to describe different levels of purchase intentions; namely:

- Inquire: That is the likelihood that the respondent would find out more about the product at their local store.

- Look for product: That is the likelihood that the respondent would look for the product in their local stores.

- Look for product information: That is the likelihood that the respondent would look for more information about the product.

- Consider: That is the likelihood that the respondent would consider buying the product.

- Purchase: That is the likelihood that the respondent would actually purchase the product if it was endorsed by the specific character in question.

These indicators werre be considered on the basis of likelihood with respondents being questioned as to whether they are likely or unlikely to inquire about the product, look for the product in store, look for information about the product, consider buying the product or actually purchase the endorsed product (Pornpitakpan, 2003a).

The three aforementioned character credibility constructs are hypothesized to positively influence the purchase intentions of the respondents to the survey (Ohanian, 1991). The reason for including purchase intention in the model is because of the high costs associated with using an endorser in an advertisement (Till, 1998). Marketers expect to gain far more value from their investment in the endorsement than simply attracting the attention of consumers (Till, 1998).

\section{Methodology}

The population which this study is focused on is university students. The reason for this is that the university students 
comprise mostly of the youth and young people are more likely to have knowledge of and previous experience with video games and video game characters. The second reason for using university students is that they have a higher spending power than younger children as well as having a broader knowledge and understanding of consumer brands. Thirdly university students were most easily accessible for the researcher and are therefore more convenient for sampling. A sample was drawn from the population, a sample was necessary because it is not possible to examine all subjects or factors of the South African population that influence the effectiveness of using video game characters as brand endorsers due to time and cost constraints in conducting the research (Krommenhoek \& Galpin, 2012).

Probability sampling is a sampling procedure in which each individual within a specified population has the same chance of being selected to be part of the sample group chosen for the research (Malhotra \& Peterson, 2006). Nonprobability sampling is a sampling technique that relies on the judgement of the researcher instead of using chance selection procedures to select individuals for the sample group (Malhotra \& Peterson, 2006). Nonprobability sampling was the technique best suited for the research design which was used.

The sample size was determined through the use of Raosoft sample size calculator. Raosoft is statistical software used in the calculation of sample size. Raosoft takes into consideration four factors in determining sample size. These factors include the margin of error, the confidence level, the population and the response distribution. Using Raosoft sample size calculator, with a margin of error of $5 \%$, a confidence level of $95 \%$, a population size of approximately 6000 , and a response distribution of $50 \%$, the minimum recommended sample size was calculated to be 362 people.

The collection of primary data was done by distributing the questionnaire to a sample of 484 individuals. The questionnaire was distributed at the University of the Witwatersrand (Wits University) in Johannesburg, South Africa, to a sample of students who were able to complete them. Thereafter the questionnaires were collected, and then coded, and the results were analysed using SAS enterprise guide 4.2. Various secondary research sources were used such as journal articles, textbooks, websites, and newspapers.

A questionnaire was designed based on the proposed model for this research. A test pilot was run on this questionnaire, where 45 respondents were asked to evaluate the questionnaire and to highlight any problems that the respondents feel may exist. This was to ensure that the respondents have the ability to understand as well as to appropriately answer the questions in the research questionnaire. There were no changes made to the questionnaire after the pilot study was run.

In an attempt to provide valid and concise data, free of bias or deception certain ethical considerations were taken into account in order to ensure that the data is legitimate, unbiased and free of any errors. All participants were asked to provide informed consent before participating in the research. All surveys were administered to participants voluntarily and they were free to participate in the survey or exit the survey at any time at their own discretion. In addition all information collected from the survey was held as confidential and will not be shared with any individual other than as part of the congregated results of the survey. To ensure confidentiality all the surveys were anonymous and no contact information was required in the survey. Ethical approval was also given by the University of the Witwatersrand and a certificate of approval was received for the research.

\section{Reliablity and Validity}

According to Malhotra and Peterson (2006), the reliability and validity of test scores need to be established. The most common test for reliability in marketing studies is the use of a Cronbach's alpha calculation. A Cronbach's alpha may be defined as a measure of reliability that is the average of all possible split-half coefficients resulting from different splittings of the variable in question (Malhotra \& Peterson, 2006). This coefficient value varies from 0 to 1 , and any value which is less than 0.6 is considered to indicate an unsatisfactory reliability for that specific construct(Malhotra \& Peterson, 2006).

Below are the Cronbach's Alphas that were calculated for each of the four constructs of the scale which were tested.

Table 1: Cronbach's Alphas Scores Calculated for the study

\begin{tabular}{|l|c|}
\hline & Cronbach Alpha Scores \\
\hline Attractiveness & 0.85 \\
\hline Trustworthiness & 0.90 \\
\hline Expertise & 0.91 \\
\hline Purchase Intentions & 0.94 \\
\hline
\end{tabular}


From this table it is evident that the Cronbach alpha scores were high and thus reliable.

Table 2: Factor analysis results for the Individual Constructs

\begin{tabular}{|c|c|c|c|c|c|c|c|}
\hline \multicolumn{9}{|c|}{ Factor Pattern } \\
\hline & Factor1 & & Factor2 & & Factor3 & & Factor4 \\
\hline Attractive & 0.79868 & Trustworthy & 0.78486 & Expert & 0.81774 & Consider Buying & 0.87313 \\
\hline Classy & 0.75721 & Dependable & 0.87002 & Experienced & 0.91174 & Look Info & 0.86309 \\
\hline Beautiful & 0.87634 & Honest & 0.87314 & Knowledgeable & 0.84907 & Look Product & 0.91784 \\
\hline Elegant & 0.77635 & Reliable & 0.87908 & Qualified & 0.86503 & Inquire Product & 0.91220 \\
\hline Sexy & 0.55261 & Sincere & 0.84670 & Skilled & 0.87099 & Buy Product & 0.90559 \\
\hline
\end{tabular}

This factor analysis indicates that the variables making up the attractiveness construct all load under one factor with relatively high loadings above 0.7 accept for the sexiness variable which has a loading of 0.55 . This result is comparable to the results found in the above reliability analysis using the Cronbach's Alpha of the data.

This factor analysis also indicates that the variables making up the trustworthiness construct all load under one factor with relatively high loadings above 0.7 . The lowest loading is 0.78 . This result is comparable to the results found in the above reliability analysis using the Cronbach's Alpha of the data.

This factor analysis indicates that the variables making up the expertise construct all load under one factor with relatively high loadings above 0.8 . The lowest loading is 0.81 . This result is comparable to the results found in the above reliability analysis using the Cronbach's Alpha of the data.

This factor analysis indicates that the variables making up the purchase intention construct all load under one factor with relatively high loadings above 0.8 . The lowest loading is 0.86 . This result is comparable to the results found in the above reliability analysis using the Cronbach's Alpha of the data.

\subsection{Validity}

The validity of the scale as defined by Malhotra and Peterson (2006) is the extent to which differences in the observed scale scores reflect the true differences among the indicators of the construct which is being measured. In other words validity relates to the extent to which the scale measures what it is supposed to measure (Malhotra \& Peterson, 2006). If a scale if perfectly valid then it is also perfectly reliable. In this case neither random nor systematic error is present (Malhotra \& Peterson, 2006).

Thus if a measure is unreliable, it cannot be perfectly valid since there is at minimum some random error is present.

For this research it is important to consider the content validity of the scale, also sometimes known as the face validity of the scale. Content validity is described as the subjective but systematic evaluation of the representativeness of the variable or construct which is of interest (Malhotra \& Peterson, 2006). In order for a scale to be content valid, it must address all dimensions of the variables of interest. This is a common sense evaluation of the scale (Malhotra \& Peterson, 2006).

The purpose of this study is to investigate the effectiveness of using video game characters as brand endorsers in the place of a celebrity. Therefore, the measuring instrument, being the questionnaire, should contain the theoretical background regarding the various elements of brand endorsements and the variables which measure the effectiveness of the message source. The questionnaire that is being used has been derived from previous research done by Pornpitakpan (2003a) on university students to determine the effectiveness of celebrity message sources. This study by Pornpitakpan (2003a) was done to validate the study that was done on the source-credibility model by Ohanian (1990 and 1991). These previous studies contribute to the content validity of the questionnaire and this study.

\section{Results}

\subsection{Attractiveness and Purchase Intention}

The first linear regression analysis is testing the relationship between the perceived attractiveness of the video game character and the purchase intentions of consumers. The hypotheses for the first linear regression are as follows:

(H1): The video game character's perceived attractiveness is not significantly related to purchase intention 
Table 3: Linear regression for the Perceived Attractiveness of the Video Game Character

\begin{tabular}{|l|c|c|c|c|c|}
\hline Analysis of Variance & DF & Sum of Squares & Mean Squares & F Value & Pr $>$ F \\
\hline Source & 1 & 369.640 & 369.460 & 312.33 & $<0.0001$ \\
\hline Model & 482 & 570.441 & 1.183 & & \\
\hline Error & 483 & 940.082 & & & R-Square \\
\hline Corrected total & Coeff Var & Root MSE & Dependent Mean & 0.393 \\
\hline \multicolumn{7}{|l|}{} \\
\cline { 2 - 6 } \\
\hline Parameter Estimates & 21.431 & 1.087 & 5.076 & Pr $>$ F \\
\hline Variable & DF & Parameter Estimate & Standard Error & t Value & 0.0094 \\
\hline Intercept & 1 & 0.664 & 0.255 & 2.61 & $<0.0001$ \\
\hline Attractiveness & 1 & 0.780 & 0.044 & 17.67 & \\
\hline
\end{tabular}

The $\mathrm{P}$ value for the attractiveness variable is $<0.0001$ which is significant at the 0.05 significance level. Therefore the researcher rejects the null hypothesis $(\mathrm{H} 0)$ in favour of the alternate hypothesis $(\mathrm{H} 3)$ which states that the game characters perceived attractiveness will positively influence the purchase intentions of consumers. So the perceived attractiveness of the video game character is significantly related to the purchase intentions of consumers. This result is supported by the research which was previously done by Pornpitakpan (2003b) and Ohanian (1991); which found that the perceived attractiveness of the brand endorser has a positive relationship with the purchase intentions of consumers.

\subsection{Trustworthiness and Purchase Intention}

The second linear regression analysis is testing the relationship between the perceived trustworthiness of the video game character and the purchase intentions of consumers. The hypotheses for the second linear regression are as follows:

$(\mathrm{H} 2)$ : The video game character's perceived trustworthiness is not significantly related to purchase intention

Table 4: Linear regression for the Perceived Trustworthiness of the Video Game Character

\begin{tabular}{|l|c|c|c|c|c|}
\hline Analysis of Variance & DF & Sum of Squares & Mean Squares & F Value & Pr $>$ F \\
\hline Source & 1 & 362.373 & 362.373 & 302.34 & $<0.0001$ \\
\hline Model & 482 & 577.708 & 1.198 & & \\
\hline Error & 483 & 940.081 & & & R-Square \\
\hline Corrected total & Coeff Var & Root MSE & Dependent Mean & 0.385 \\
\hline & 21.567 & 1.095 & 5.076 & Pr $>$ F \\
\cline { 2 - 6 } \\
\hline \multicolumn{7}{|l|}{ Parameter Estimates } \\
\hline Variable & DF & Parameter Estimate & Standard Error & t Value & $<0.0001$ \\
\hline Intercept & 1 & 1.614 & 0.205 & 7.87 & $<0.0001$ \\
\hline Trustworthiness & 1 & 0.679 & 0.039 & 17.39 & \\
\hline
\end{tabular}

The $P$ value for the trustworthiness variable is $<0.0001$ which is significant at the 0.05 significance level. Therefore the researcher rejects the null hypothesis $(\mathrm{HO})$ in favour of the alternate hypothesis which states that the game characters perceived trustworthiness will positively influence the purchase intentions of consumers. So the perceived trustworthiness of the video game character is significantly related to the purchase intentions of consumers. This result is supported by the research which was previously done by Pornpitakpan (2003b) and Ohanian (1991); which found that the perceived trustworthiness of the brand endorser has a positive relationship with the purchase intentions of consumers.

\subsection{Expertise and Purchase Intention}

The third linear regression analysis is testing the relationship between the perceived expertise of the video game character and the purchase intentions of consumers. The hypotheses for the third linear regression are as follows:

(H3): The video game character's perceived expertise is not significantly related to purchase intention 
Table 5: Linear regression for the Perceived Expertise of the Video Game Character

\begin{tabular}{|l|c|c|c|c|c|}
\hline Analysis of Variance & DF & Sum of Squares & Mean Squares & F Value & Pr $>$ F \\
\hline Source & 1 & 324.702 & 342.702 & 254.33 & $<0.0001$ \\
\hline Model & 482 & 615.379 & 1.277 & & \\
\hline Error & 483 & 940.082 & & & \\
\hline Corrected total & Coeff Var & Root MSE & Dependent Mean & R-Square \\
\hline \multicolumn{5}{|l|}{} \\
\cline { 2 - 6 } \\
\cline { 2 - 6 } \\
\hline Parameter Estimates & 22.260 & 1.130 & 5.076 & 0.345 \\
\hline Variable & DF & Parameter Estimate & Standard Error & t Value & Pr $>$ F \\
\hline Intercept & 1 & 1.376 & 0.237 & 5.79 & $<0.0001$ \\
\hline Expertise & 1 & 0.660 & 0.041 & 15.95 & $<0.0001$ \\
\hline
\end{tabular}

The $P$ value for the expertise variable is $<0.0001$ which is significant at the 0.05 significance level. Therefore the researcher rejects the null hypothesis $(\mathrm{H} 0)$ in favour of the alternate hypothesis which states that the game characters perceived expertise will positively influence the purchase intentions of consumers. So the perceived expertise of the video game character is significantly related to the purchase intentions of consumers. This result is supported by the research which was previously done by Pornpitakpan (2003a) and Ohanian (1991); which found that the perceived expertise of the brand endorser has a positive relationship with the purchase intentions of consumers.

\subsection{Gender and Purchase Intention}

\subsubsection{T-Test for the Difference Between Purchase Intentions for Respondents of Different Genders}

The hypotheses for the first t-test are as follows:

$(\mathrm{H} 4)$ : There is no difference between the responses of males and females in relation to their purchase intentions.

Table 6: T-Test for the Difference Between Purchase Intentions for Respondents of Different Genders

\begin{tabular}{|c|c|}
\hline T-Test on Gender & P Value \\
\hline Pooled Method & 0.115 \\
\hline Satterwaite Method & 0.120 \\
\hline Equality of Variances & 0.082 \\
\hline
\end{tabular}

The $P$ value of the equality of variances is 0.08 , which is not significant at the 0.05 level of significance. Therefore the pooled variances were used. The $P$ value for the pooled method is 0.11 ; this is not significant at the 0.05 level of significance. Therefore we fail to reject the null hypothesis $(\mathrm{HO})$ as there is insignificant evidence to accept the alternate hypothesis $(\mathrm{H} 1)$. What this means is that there is no significant differences between the purchase intentions of males and females after they have been exposed to the adverts used in this research.

\subsection{Engagement with video game and purchase intentions}

\subsubsection{T-Test for the Difference Between Purchase Intentions for Respondents with Different Engagement in Video Games}

The hypotheses for the second t-test are as follows:

(H5): There is no difference between the responses of those respondents which play video games and those respondents which do not play video games in relation to their purchase intentions.

Table 7: T-Test for the Difference Between Purchase Intentions for Respondents with Different Engagement in Video Games

\begin{tabular}{|c|c|}
\hline T-Test on Gender & P Value \\
\hline Pooled Method & 0.002 \\
\hline Satterwaite Method & 0.002 \\
\hline Equality of Variances & 0.716 \\
\hline
\end{tabular}


The $P$ value of the equality of variances is 0.716 ; which is not significant at the 0.05 level of significance. Therefore the pooled variances were used. The P value for the pooled method is 0.002 ; this is very significant at the 0.05 level of significance. Therefore we reject the null hypothesis $(\mathrm{HO})$ in favour of the alternate hypothesis which states that there is no difference between the responses of those respondents which play video games and those respondents which do not play video games in relation to their purchase intentions. Thus it can be concluded that the purchase intentions of the respondents differ depending on the respondents' engagement with video games. What this means is that those respondents who play video games and those respondents who do not play video games differ in their intentions to purchase the brand which is being endorsed after being exposed to the advertisement.

\subsection{Attractiveness, Trustworthiness, Expertise and Purchase Intention}

The last regression analysis is testing the relationship between the perceived attractiveness, trustworthiness and expertise of the video game character and the purchase intentions of consumers. The hypotheses for the fourth linear regression are as follows:

(H6): The video game character's perceived Attractiveness, Trustworthiness and Expertise together are not significantly related to purchase intention.

Table 8: Multiple Linear regression for the Perceived Attractiveness, Trustworthiness and Expertise of the Video Game Character

\begin{tabular}{|l|c|c|c|c|c|}
\hline Analysis of Variance & DF & Sum of Squares & Mean Squares & F Value & Pr $>$ F \\
\hline Source & 3 & 440.348 & 146.782 & 140.99 & $<0.0001$ \\
\hline Model & 480 & 499.733 & 1.041 & & \\
\hline Error & 483 & 940.082 & & & R-Square \\
\hline Corrected total & Coeff Var & Root MSE & Dependent Mean & 0.468 \\
\hline \multicolumn{7}{|l|}{} & 1.020 & 5.076 & Pr $>$ F \\
\cline { 2 - 6 } & 20.101 & Standard Error & t Value & 0.3203 \\
\hline Parameter Estimates & df & Parameter Estimate & 0.248 & 0.99 & $<0.0001$ \\
\hline Variable & 1 & 0.247 & 0.060 & 6.81 & $<0.0001$ \\
\hline Intercept & 1 & 0.415 & 0.060 & 4.98 & 0.0055 \\
\hline Attractiveness & 1 & 0.0300 & 0.061 & 2.79 & \\
\hline Trustworthiness & 1 & 0.170 & & & \\
\hline Expertise &
\end{tabular}

The $P$ value for the attractiveness variable is $<0.0001$ this is significant at the 0.05 . The $P$ value for the trustworthiness variable is $<0.0001$ this is significant at the 0.05 The $P$ value for the expertise variable is 0.0055 this is significant at the 0.05 significance level. Therefore the researcher rejects the null hypothesis in favour of the alternate hypothesis which states that the game characters perceived attractiveness, trustworthiness and expertise will positively influence the purchase intentions of consumers. So the perceived attractiveness, trustworthiness and expertise of the video game character is significantly related to the purchase intentions of consumers. This result is supported by the research which was previously done by Pornpitakpan (2003b) and Ohanian (1991); which found that the perceived attractiveness, trustworthiness and expertise of the brand endorser has a positive relationship with the purchase intentions of consumers.

These afore-mentioned results required the modified source credibility model to be revised in order to demonstrate the correct relationships between the constructs. Only the relationship between gender and purchase intentions was shown to be insignificant, therefore it was removed from the model. The other constructs have been demonstrated to all have significant relationships with the purchase intentions of the respondents after they have been exposed to the advertisement. The revised model is illustrated below in figure 2 . 
Figure 2: The Revised Modified Source Credibility Model

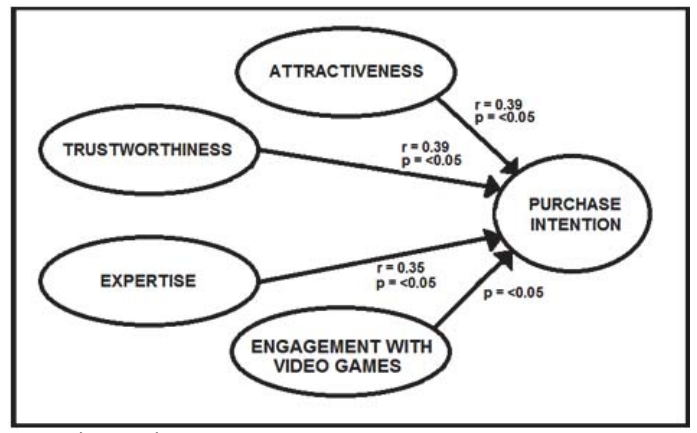

Source: Adapted from Pornpitakpan (2003a)

\section{Discussion}

This research had six main objectives which involved the video game characters perceived attractiveness, trustworthiness, and expertise and the effects these constructs had on the purchase intentions of consumers both individually and collectively. Also the research looked at the difference in the purchase intentions of respondents of different genders as well as the difference in the purchase intentions of respondents with different engagements with video games.

The first finding was that the video game character's perceived that attractiveness positively influence the purchase intentions of consumers. Essentially what this means is that, when using a video game character as a brand endorser, if consumers perceive the character to be attractive then this will positively influence those consumers' intentions to purchase the brand which is being endorsed.

The second finding was that the video game character's perceived trustworthiness positively influence the purchase intentions of consumers. What this means is that, when using a video game character as a brand endorser, if consumers perceive the character to be trustworthy then this will positively influence those consumers' intentions to purchase the brand which is being endorsed.

The third finding was that the video game character's perceived expertise positively influence the purchase intentions of consumers. In essence, what this means is that, when using a video game character as a brand endorser, if consumers perceive the character to be an expert in relation to the brand which is being endorsed then this will positively influence those consumers' intentions to purchase the brand.

The fourth finding was that the video game character's perceived attractiveness, trustworthiness, and expertise together will all positively influence the purchase intentions of consumers. What this means is that, when using a video game character as a brand endorser, if consumers perceive the character to be attractive, trustworthy, as well as an expert in relation to the brand being endorsed then this will positively influence those consumers' intentions to purchase the brand.

The fifth finding was that there was no significant difference between respondents of different genders when it came to their purchase intentions. What this means essentially is that the advertising strategy of using video game characters as brand endorsers is equally effective for targeting male consumers as it is for targeting female consumers. So video game characters can be used to endorse brands which are targeted at either male consumers or female consumers, or even both groups of consumers.

The final finding was that there was a significant difference between respondents who play video games and respondents who do not play video games when it comes to their purchase intentions. What this means is that this endorsement strategy is more effective on some consumer segments than others. It predicts that this brand endorsement strategy will be more effective for targeting consumers who engage with playing video games over those consumes that do not engage with video games.

\section{Recommendatons and Managerial Implications}

The main implication for managers is that if marketers decide to use a video game character as a brand endorser in the 
future, then the marketers should investigate which video game characters their target audience perceives to be attractive, trustworthy, and an expert in relation to the brand's product which is being endorsed. If managers are able to do this, then the video game character being used as a brand endorser should have a positive effect on consumers purchase intentions.

It can be recommended that marketers invest time in deciding whether or not the brand will be able to use a video game character in place of a celebrity to endorse the brand's products. This is because the use of video game characters has been shown in this research to positively affect consumers purchase intentions, in the same way that ordinary celebrities do, but they also have several benefits which reduce the risks of using a brand endorser which are normally associated with the use of ordinary celebrities.

It can also be recommended that video game companies seek opportunities to create partnerships with marketers to use their characters as brand endorsers. The reason for this is that these kinds of partnerships have been shown to be beneficial to both partners in the past according to Avery, et al (2006), as discussed in the literature review.

There was no significant difference in the purchase intentions of respondents who were of different genders. The implication of this is that this form of endorsement is equally effective for targeting both male and female consumers. So marketers who wish to employ this form of endorsement can target both male and female consumers and which gives the marketer more opportunities to target specific market segments.

It was shown in figure 2, that there was a significant difference in the purchase intentions of consumers who play video games as opposed to those consumers who do not play video games, after they have been exposed to the advertisement. The implication here is that if marketers have information suggesting there is an opportunity to expand their brand into market segments where there are many consumers who engage in video games then this strategy of using video game characters as brand endorsers is a powerful marketing tool to attract these consumers to the brand.

This implication is important because of the size and rapid growth of the video game industry on a global scale. The video game market is the fastest growing entertainment industry in the world (Caperton, 2012; Whitford, 2012; Jackson, 2011). This research found that $62 \%$ of the respondents engaged in video games as opposed to $38 \%$ that did not play any form of video games. This would suggest that there is a great opportunity for marketers to target new market segments through the use of video game characters as brand endorsers.

This implication is supported by the research which was conducted by Avery, et al (2006) which suggested that the video game industry is the largest entertainment industry globally. Also gamers, or in other words those consumers that play video games, represent a huge untapped market. Jones, et al (2008) state that more than $50 \%$ of adults in first world countries play video games of some kind. The gaming industry in South Africa is not as well developed as those in first world countries, but there is rapid growth within the South African gaming industry and which in turn is growing new opportunities for advertisers and marketers (Lamothe, 2012).

\section{Suggestions for Future Research}

The first opportunities for future research are with investigating any other constructs which may have a mediating effect on the model which was used. Examples of such construct are the product-endorser match up and the meaning transfer construct. This research has tried to remove as much bias as possible by using video game characters which are perceived to fit with the products which are being endorsed.

Firstly future research could be done on how well the video game character matches up with the brand and the characteristics of the brand which is being endorsed, and what effect this has on consumers' perceptions of the endorsement and the effect it has on consumers purchase intentions. Secondly future research can be done on if meanings can be transferred from the video game character to the brand and from the brand to consumers, what kinds of meanings can be transferred this way, and what affect the transfer of meanings has on the purchase intentions of consumers.

This study was also limited by the time and monetary constraints which were in place. Due to these limitations the study was done using non-probability sampling methods. The use of non-probability sampling means that the results of this research are limited in terms of generalizability to other populations. Future research in this area may be done using probability sampling to solve this problem of generalizability.

Future research should also examine the impact of consumer involvement as well as confidence in the product as mediating variables in the source-credibility research model. This research was done under conditions of lowinvolvement, where-as future research may be done under conditions of high-involvement. Future research can also be done to investigate the differences of using high-involvement versus low-involvement products and how these differences may affect the purchasing intentions of the target population. 
In the future researchers could also conduct comparative study between video game characters and ordinary human celebrities. The research can compare the perceived attractiveness, trustworthiness, and expertise of the celebrity and the game characters and investigate if there are differences in the affects these perceptions have on the consumers purchase intentions.

Future research could also focus on constructs which are not discussed in this research such as the aspirational aspect of the endorser. Essentially this construct would refer to the desire of consumers to be like the endorser or to share the same characteristics which they perceive the endorser to have. This construct may also be related to the meaning transfer construct described earlier.

Future research could investigate which target markets are most suitable for this form of endorsements and also which kind of products are best suitable for being endorsed in this way. There could be a different response when high involvement products are used as opposed to low involvement products. Target markets may be very different for different brands so it would be beneficial to have a more extensive study on which consumers this form of endorsement is more effective on. As was discussed earlier this is an area of research which is under studied so there are many areas where further research could be of use to marketers.

\section{Conclusion}

This research found that video game characters, which are perceived by consumers to be attractive, trustworthy and experts in relation to the product being endorsed, can be effective at positively influencing consumers purchase intentions. This is comparable to the research findings by Pornpitakpan (2003b) on the use of celebrity brand endorsers. Thus, given an appropriate target market, video game characters may be used in place of normal celebrities as brand endorsers.

Considering the risks which are present in the use of celebrities as brand endorsers and the benefits which were discussed previously for the use of video game characters, in some situations it would be preferable to use a video game character in place of an ordinary celebrity to endorse a brand.

This research included a comprehensive literature review and also conducted an empirical quantitative research study into the effectiveness of using a video game character as a brand endorser. In conclusion to this study it can be said that given the popularity of using endorsers in advertising, and the statistical results of this research, the issue of using video game characters in place of celebrity endorsers should receive more attention from both advertising practitioners and marketing researchers in the future.

The aim of this research paper was to investigate if it is effective to use a video game character in place of a celebrity to endorse a brand. From the findings of the statistical analysis of the data collected, we can conclude that it is possible to use a video game character in place of a celebrity to endorse a brand.

Given the popularity of using spokespersons in advertising, the issue of using video game characters as celebrity endorsers should receive more attention from both advertising practitioners and marketing researchers.

\section{References}

Amos, C., Holmes, G. \& Strutton, D. (2008). Exploring the Relationship Between Celebrity Endorser Effects and Advertising Effectiveness. International Journal of Advertising, pp. 209-234.

Anderson, C. et al. (2007). Celebrity Status. Sociological Theory, 25(2), pp. 347-367.

Avery, M., Ferrand, T., Nichols, D. \& Rowley, T.(2006). Brands and Gaming: Are you Ready to Play?. Young Consumers, Quarter 1, pp. 8-13.

Boshoff, C. et al.( 2008). Marketing, Third Eddition. Cape Town: Oxford University Press South Africa.

Bustami, M. \& Fikry, A. (2012). The Impact of Teenagers' Gener and Product Importance on Family Decision to Purchase Game Consoles in Malaysia. Business Strategy Series, 13(2), pp. 89 - 95.

Caperton, H. (2012). Calling All Girls: The Video Gaming Industry Offers Exceptional Opportunities to Young Women. Huffington Post, (Accessed on 26 April 2012), [Available at http://www.huffintonpost.com/idit-harel-/calling-all-girls_b_1444526.html].

Erdogan, B. (1999). Celebrity Endorsement: A Literature Review. Journal of Marketing Management, 15(1), pp. 291-314.

Jackson, N.(2011). Infographic:Video Game Industry Statistics. The Atlantic, (accessed on 15 April 2012), [Available at http://www.theatlanit.com/technology/archive/2011/06 /infographic-video-game-i ndustry-statistics/239665/].

Jaiprakash, A.(2008). A Conceptual Research on the Association Between Celebrity Endorsement, Brand Image and Brand Equity. The Icfai University Journal of Marketing Management, vol. 7, no. 4, pp. 54-64.

Krommenhoek, R.E. and J.S. Galpin (2012), "Course Notes for Statistical Research Design and Analysis," Johannesburg: University of the Witwatersrand.

Lamothe, L.(2012). The Imminent Rise of Electronic Game Development in th SA Advertising and Marketing Industry. Luma Arcade 
(accessed on the 10-05-2012) [Available at http://animationssa.org/articles/luma-arcade-\%E2\%80\%93-imminent-rise-electronicgame-development-sa-advertising-and0marketing-indust.

Malhotra, N. \& Peterson, M., 2006. Basic Marketing Research: a Decision-Making Approach, second edition. New Jersey: Pearson Prentice Hall.

Patel, P. (2009). Impact of Celebrity Endorsement on Brand Acceptance. The Icfai University Journal of Consumer Behavior, 4(1), pp. 36-45.

Patel, P. (2009). Impact of Celebrity Endorsement on Brand Acceptance. The Icfai University Journal of Consumer Behavior, vol. 4, no. 1 , pp. 36-45.

Peter, R.. (2011). Brand Endorsements by Video Game Characters?. Do Gaming, (Accessed on 14 april 2012), [Available at http://gaming.do.co.za/articles/opinion/brand_endorsement_by_gaming_characters.htm].

Pornpitakpan, C. (2003)a. Validation of the Celebrity Endorsers' Credibility Scale: Evidence from Asians. Journal of Marketing Management, 19(2), pp. 179-195.

Pornpitakpan, C. (2003)b. The effect of Celebrity Endorsers' Perceived Credibility on Product Purchase Intention: The Case of Singaporeans. Journal of Intenational Consumer Marketing, 16 (2), pp.55-74.

Shimp, T. \& Till, B. (1998). Endorsers in Advertising: The Case of Negative Celebrity Information. Journal of Advertising, 27(1), pp. 6782.

Whitford, S. (2012). South African Game Sales Continue to Rise. Do Gaming, (Accessed on 15 April 2012), [Available at http://gaming.do.co.za/articles/localnews/south_africa_game_sales_continue_to_rise.] 